\title{
Spatial Explorations and Digital Traces: Experiences of Legal Blindness through Filmmaking
}

\author{
Adolfo Ruiz * and Megan Strickfaden \\ Received: 3 December 2015; Accepted: 31 December 2015; Published: 6 January 2016 \\ Academic Editor: Gregor Wolbring \\ Department of Human Ecology, University of Alberta, 302 Human Ecology Building, Edmonton, AB T6G 2N1, \\ Canada; megan.strickfaden@ualberta.ca \\ * Correspondence: adolfo@ualberta.ca; Tel.: +1-780-289-7915
}

\begin{abstract}
Descriptions of legal blindness, as lived experience-involving continual movement between the world of sightedness and blindness-are largely absent within medical models of disability. In an effort to challenge depictions of blindness as pathology, researchers in this project worked with participants who are legally blind, in a co-designed exploration of built spaces in the city of Edmonton, Canada. In this article we describe a collaborative research method through which participants shared stories while recording their movement through a shopping mall, an art gallery, and a gym. Through this project, participants often took the lead, determining the content and context of urban journeys. Stories and images shared through this collaboration suggest that legal blindness is an alternative way of knowing the world, with unique perceptual experiences, navigational strategies, and complexity that is often unacknowledged within a medically constructed blindness/sightedness binary. In describing the complex relationship between participants, researchers, architecture, and technology we will combine narrative forms of writing with actor-network theory. The sharing of stories, along with lived experiences has led to a project that revolves around ability, as opposed to disability. A link to the film is provided at the end of this article.
\end{abstract}

Keywords: ability; collaboration; disability; material culture; storytelling; urban journey; voices

\section{Introduction}

Sometimes... when I see another drawing, painting, I don't know why but I just feel like I can do it. It's easy for me... I can draw it too. (Shafi)

I like to play the flute... I do a little bit of computer work on the side. Just for fun, just for friends. (Eleanor)

I think people need to know we don't just sit at home and wait for people to take us around. We're out here in the world. (Carol)

This is a story that began with three conversations. Each one opened up a unique world of personal journeys, urban travel, collaborative filmmaking, and more stories. The film that emerged from this process is Light in the Borderlands, a short documentary that was narrated and recorded by people who are legally blind. Each person in the film communicates a unique experience of the world.

Light in the Borderlands is both a film and a research project that explores built environments. Participants from the Canadian National Institute for the Blind (CNIB) and researchers in human ecology and design studies from the University of Alberta came together to make this video. Behind the film we uncover the story of an ethnographic collaboration between researchers and participants.

The ethnographic work that led to the making of this film, opens up other stories about navigation within the city. These stories reflect the entangled pathways along which human and non-human 
entities (which we refer to as actors) travelled [1] (p. 70). Through these interwoven paths, actors "flow, mix and mutate" [1] (p. 86). Our conceptual framework is derived from "the actor network" of Bruno Latour [2] (p. 141). Throughout this text we reveal the many actors that contribute to Light in the Borderlands-some are absent and some are present in the film. The first section of our story deals with the actors who are absent from the film: the voices of researchers, the camera, along with the dialogue and relationships that emerged through ethnographic work. Within this section we reveal how our research involved planning at the initial stage, but largely evolved through "improvisatory movement", working things out as we moved along [1] (p. 178). In other words our dialogue, along with the filmmaking process, was largely unstructured.

The second section of our story illustrates the actors that are present (as visual or audio material): image, darkness, light, participant voices and sound. These are actors that make an overt contribution to the research. They were documented during fieldwork, and at times emerged through the filmmaking process.

Our actors, present and absent, human and non-human, are endowed with agency. Material components of this research such as architectural spaces, artwork, or the camera have agency and are bound up in relations with other artifacts, light, sound, participants, and researchers [1] (p. 91). There are no "passive objects" in this story [1] (p. 91).

The many actors involved in the ethnographic encounter contribute to the voices and textures of Light in the Borderlands. The actors that populate this world travel through an entangled "meshwork" of pathways where people, architecture, cameras, and buses temporarily encounter one another [1] (p. 149). These entangled paths illustrate both the movement and story of each actor-an idea described by Ingold when he writes that "the things of this world are their stories, identified not by fixed attributes but by their paths of movement in an unfolding field of relations" [1] (p. 160).

Throughout this research the paths of movement evolve through built spaces within the city of Edmonton. These are the spaces from which stories emerge. These are also the spaces that embody the borderland between the sighted and blind world. Within this region, legally blind people "are pressed to migrate back and forth" from one world to the other [3] (p. 185). The notion of legal blindness as a borderland is based on Beth Omansky's book, Borderlands of Blindness. Eleanor, Shafi, and Carol are the three participants who, through the making of this film, explore the borderland region. Through their journeys this project explores the notion of "plural authorship", as the narrative and visual content of the film emerge through interaction between participants and researchers [4] (p. 246).

\subsection{Theory and Objectives}

The objective behind this research was to explore the unique "phenomenological and sociocultural experiences" of people who are legally blind by making a film with participants [3] (p. 5). According to Beth Omansky, people who are legally blind have perceptual experiences that are "vastly different from those of either sighted or totally blind people" [3] (p. 5). As researchers in the fields of design and material culture, we chose to explore the ambiguous and often misunderstood experiences of legal blindness through a participatory form of video ethnography [5] (p. 110). Light in the Borderlands is a form of research where the end product is an artifact- "where the thinking is, so to speak, embodied" in the video [6] (p. 5). As we worked with participants, technology played a significant role in generating knowledge. The film that emerged from this research possesses specific technical characteristics, made using a particular type of technology (a standard definition camera). Descriptions of the camera, the film, and how these relate to the research experience, will be shared in this article. These descriptions will highlight how a camera was used to embody perceptual experiences, while also facilitating collaborative fieldwork.

Using Omansky's literature as a starting point, our project explores an alternative form of research into the perceptions and experiences of legal blindness. Our research is based on a cultural model of disability by exploring legal blindness through co-designed urban explorations and open-ended conversations. Unlike projects operating within an "ideology of normalization" which according to 
Devlieger, Rusch, and Pfeiffer are embodied in disciplines such as medicine and psychology, this research emphasizes dialogue, perception, and place in the telling of stories [7] (p. 9).

The combined process of being in a meaningful location and telling stories is, on the one hand, derived from Jon Anderson's notion of "conversations in place" [8] (p. 254). Anderson's methodology, also referred to as "talking whilst walking" taps into the interconnectedness of mind and place in order to elicit knowledge of environments and past experiences [8] (p. 254). On the other hand, the storytelling component of this research is inspired by Rod Michalko's idea of elevating "blindness to the position of something that provokes thought" [9] (p. 4). In The Mystery of the Eye and the Shadow of Blindness, Michalko offers the reader a unique "conception of blindness" by giving voice to the "many tellers of the story of blindness" [9] (p. 4). Through storytelling, Light in the Borderlands also provides participants with opportunities to share lived experiences. According to Charlotte Linde, narrative plays a role in "the establishment of self" [10] (p. 98). Moreover, narrative is "a major resource for conveying that self to and negotiating that self with others" [10] (p. 98).

The visual approach to storytelling used in this research is derived from a reflexive use of video, which, as Sarah Pink writes, is not simply used as a means to "record data, but as a medium through which ethnographic knowledge is created" [5] (p. 96). Walking, talking, sharing stories, and recording footage, therefore, were equally integral to the knowledge generated through this research. This eclectic combination of activities facilitated a thoughtful, unhurried, and creative approach to the collaboration described in this article.

\subsection{The Film as a Material Artifact}

Light in the Borderlands resides in multiple domains. It is a documentary project, an ethnographic study, a travelogue, a form of participatory design, and an experimental collage of images. As researchers we consider it appropriate for this film to embody multiple approaches to narrative. In other words, we embrace the fact that Light in the Borderlands is a documentary film and an ethnographic study, a travelogue and an experimental collage.

Categorizing the film in only one of these domains would limit the scope and understanding of this project. Like the participants in this research, this film does not belong to a single category. Instead this work explores "the experience of living between two or more cultural regimes of knowledge" - an approach that is akin to Laura Mark's description of "intercultural cinema" [11] (p. 1). In the case of this film, each narrator negotiates a unique path between the cultural regimes of blindness and sightedness [11] (p. 1). Each path is described through audio and video footage, communicating the journey of each participant.

A close look at the video footage reveals the raw material of Light in the Borderlands: pixels. A mosaic of shifting pixels illustrates each journey. $720 \times 480$ pixels make up each frame of the film.

A pixel count of $720 \times 480$ pixels is low in comparison with high definition resolution $(1920 \times 1080$ pixels $)$, and digital cinema formats $(4096 \times 2160$ pixels $)$. The resolution of this film, therefore, creates a unique viewing experience as the grainy footage exposes visible pixilation when enlarged through a projector. Light in the Borderlands is a highly malleable material artifact-with the use of a projector it can be magnified in scale.

Through enlargement the film reveals low visual information. Captured imagery and color may appear as a blurred and muddy field. Like the shifting experiences communicated by each participant, the texture of this film appears to fluctuate in an ambiguous mesh of grey pixels and light.

\section{Absent Actors}

\subsection{The Art of Dialogue: Behind the Scenes of Light in the Borderlands}

Films tend to have rigid boundaries indicating the beginning and end of a story. These boundaries are sometimes determined by opening and closing titles. Light in the Borderlands is no exception. The entire film is encapsulated within a concise documentary framework, bounded on each end by 
text indicating a start and conclusion. If we consider, however, the dialogue, before and after the film was made, between participants and researchers, along with the involvement of other human and nonhuman actors, these boundaries may be extended.

Considering this expanded notion of boundaries, the beginning of Light in the Borderlands can be traced back to the summer of 2012. The film was conceived while I (Adolfo Ruiz, author one) worked as a research assistant in the Department of Human Ecology (University of Alberta) with Megan Strickfaden (author two) on a project exploring how disability is situated in the design process. That summer, Strickfaden curated In Focus, a photo exhibition based on the work of blind and partially sighted photographers. The idea behind the exhibition, based on the use of photovoice (a method used for thematic explorations in community-based work), inspired Light in the Borderlands.

Participants in our film became involved through the Canadian National Institute for the Blind (CNIB) after author two got in touch with the organization. Expressing interest in the study, Shafi, Eleanor, and Carol were initially contacted via telephone-the project was introduced, and an initial meeting was planned. The remainder of this section is made up of three parts-each one includes the creative process, meetings, and overall experience of working with each participant, as described by author one. Within each sub-section, we begin by situating the participant within this research, noting their connection and contribution to the film, and describing our first meeting. We continue by discussing the process of working together, and conclude with an urban journey (determined by each participant). Through the making of Light in the Borderlands, fieldwork was a collaborative experience, as participants provided verbal and visual content for the film. In this section we describe fieldwork as a series of dialogues and evolving relationships between participants and researchers.

HANDS-ON RESEARCH (SHAFI'S JOURNEY): Of all three participants, Shafi's interests most naturally suited the methodology of research through filmmaking. In his journey we learn that life is an opportunity for artistic creation, musical exploration, and storytelling. Shafi's interests were also a good fit with my own background in art and design.

Shafi was the first participant I met [12]. Content for Light in the Borderlands emerged during our first meeting at a coffee shop in north Edmonton in the summer of 2012. It was through this initial dialogue that the project began to take shape. More importantly, Shafi's stories, enthusiasm and high school involvement in photography and film convinced me that co-creating a film was possible.

This research was my first experience with disability. I came into the project as an outsider. But Shafi's warm, open, and creative disposition was reassuring. During our conversation I found common ground in talking about drawing, film, and music. As the first encounter between participant and researcher, my initial meeting with Shafi is in many ways the story before the story, which I will share over the next several paragraphs.

I initially met Shafi in a north Edmonton coffee shop, very close to his house, on a warm summer afternoon in July. I arrived a few minutes early (just before 2:00 pm). I purchased a tea and looked around at the clean, but rather stagnant, air conditioned interior. I tried finding a good place to sit. Loud noises emanated from the baristas and coffee machines. From a sensory perspective, the interior of the coffee shop felt cold, and generated too much noise for a recorded conversation to take place. I walked outside where I had the option of sitting at a table. As I tested the recorder I realized that I was in the middle of a large parking lot surrounded by box stores. The recorder was picking up constant traffic moving through the area. Learning that both interior and exterior provided less than ideal conditions for the interview, I walked back inside and decided to read a newspaper as I waited for Shafi. I did not know what Shafi looked like.

It was 2:05 pm when a young man, stylish, late teens, with a slim build and a mod haircut walked into the coffee shop. He appeared to have perfect vision as he looked around the establishment. We even made eye contact, as he began to interact with his phone. I assumed this was not Shafi. I looked away and started reading a new article in the newspaper.

I cautiously sampled my hot cup of tea. As I continued reading, my cell phone rang. I picked it up and it was Shafi (the young man who had just walked in) calling from inside the coffee shop. 
I approached him and we shook hands. I thanked him for coming, and he jokingly commented on how helpful his phone was in finding me. He was soft-spoken and had a kind, gentle demeanor. I bought him a coffee. The interior space seemed to be getting noisier as new customers walked in so I proposed we sit and chat outside.

Our conversation began on very casual terms. I was curious about his art practice, and was surprised to learn of his interest in music and filmmaking. He was happy to share stories about recent and past events in his life. During the last year he completed a video as part of a competition at his high school. He was part of a social justice group that raised money for local charities, providing funds for the construction of a school in Afghanistan. Furthermore he played the guitar and was planning to start a band. Born in Afghanistan, and raised in both India and Canada, Shafi's linguistic ability (at nineteen he speaks five languages) reflect a life of travel and intercultural experiences.

During our conversation I asked a set of questions (standard for each participant) that covered basic information on urban travel and mobility. In response to the first question (what places do you most often visit?), Shafi indicated school, mosque, and hospital. In response to the second question (what places do you most like to visit?) he referred to the Art Gallery of Alberta and the Royal Alberta Museum. We easily agreed on the art gallery as the location for our second meeting. I also recommended he bring some of his artwork to the excursion.

Less than a month after this first meeting, in early August, I once again met Shafi in north Edmonton. This time we drove to the Art Gallery of Alberta located in the central part of the city. We spent over an hour walking through the building. The space brought forth new conversations but also revealed unexpected barriers. Not surprisingly, the gallery staff had strict rules on where and where not to film. More importantly, the dim lighting in the exhibit areas made the artwork difficult for Shafi to see. Although there were several large scale paintings and installation works, the darkness and rules against touching, made large parts of the exhibitions inaccessible to Shafi. There was a moment where he put his hand on a sculpture, but was quickly asked to not touch by security personnel. Shafi's desire to explore the tactile qualities of exhibited material was discussed after the gallery visit.

When I put my hands on the art I can see more. I can feel it, I can see it is real art, it's not just a picture.

After our gallery visit we had the opportunity to put our hands on real art as we recorded and discussed drawings made by Shafi. The transition from a dark and distancing gallery visit to a hands-on, engaging discussion about the experience of creating art, highlighted a key theme of this project: ability. Through the presentation of these sketches, Shafi revealed his talent, while also sharing memories and anecdotes associated with each image. Through our meetings in different locations, and conversations about art-making, collaborations with Shafi reveal unique lived experiences of legal blindness. These experiences are rich and complex, suggestive of the dynamic, often misunderstood, borderland experience described by Omansky [3] (p. 5).

CONVERSATIONS AT A FOOD COURT (ELEANOR'S JOURNEY): Eleanor was the second participant we worked with. Of all participants, her stories come closest to familiar notions of blindness. She is the only participant, for example, to discuss the use of a cane. By not basing her journey on an overtly creative activity (as was the case with Shafi), her discussion focused on everyday experiences of mobility. The knowledge shared by Eleanor is valuable in understanding the challenges as well as the strategies of independent travel within Edmonton. Her description of environmental light, public transportation, and shopping embodies another way of knowing a built space from the perspective of a woman who is partially sighted.

I first met Eleanor in September, 2012, at the Edmonton branch of the CNIB where she worked at the time. She was friendly and very helpful in finding a conference room for our first meeting. Eleanor was generous in providing time and knowledge throughout this research. Her kind disposition and sense of humor made our co-designed journey enjoyable. She provided some of the most insightful and articulate descriptions of the research. However, the in-depth insight and knowledge that comes through in her story (as communicated in the film) did not emerge until our second meeting in the mall. 
Our first meeting was efficient but lacked spontaneity. The restrained nature of this discussion was due to the structured nature of the interview. Unlike the first encounters with Shafi (and later with Carol), this meeting mostly revolved around predetermined questions. More importantly, this was the only meeting that took place in a formal work setting. With limited time, our dialogue was more to the point, as I aimed to have a series of questions answered within $30 \mathrm{~min}$. We managed to cover key topics that eventually led to our second meeting at City Centre Mall, but an active dialogue had not yet been established.

Our second meeting began, one month later, at a coffee shop across the street from Eleanor's work. It was late in the afternoon on a weekday. Eleanor had finished her job for the day. The sky was overcast, with a light sprinkling of rain. We each ordered a cup of tea and casually discussed the plan for this second interview/journey. We then took a bus to City Centre Mall, about $4 \mathrm{~km}$ from the coffee shop. The changing settings, and unstructured nature of our conversation produced a dialogue that, unlike our first meeting, was effortless and continual.

Our journey in the mall began with an unplanned stop at a large department store inside the mall where Eleanor purchased an umbrella for her return home. The insight provided by Eleanor, later in the interview, emerged from informal dialogue, like the one below on lost umbrellas.

Adolfo: So here they are.

Eleanor: This is them is it?

A: Yup. Oh, and they've got more here on the side.

E: Okay I've got one of those. Oh that looks nice. I'll just grab that one. That one might be easier to see. $\mathrm{Na}$, I'll just grab this one. Good enough.

A: Okay?

E: Okay.

A: I'm notorious for losing umbrellas.

E: I leave them on buses all the time. I think I lost three this year already.

A: Did you?

E: Oh yeah. I usually hook it on the seat or something like that, and then I don't think about it.

A: The ones I usually have are really small ones, so it's easy to lose.

E: Oh the small ones I don't lose because I stick those in my backpack. It's the big ones-this one might not last me very long (laughs). These are the ones I forget.

A: Well, hopefully someone else makes good use of these lost umbrellas.

E: I hope so.

Throughout this journey, specific places within the mall elicited memories of old businesses. After purchasing the umbrella Eleanor remembered the department store that used to be in the space where we purchased the umbrella.

E: This store used to be Woodwards.

A: Oh really.

E: Woodwards used to have a special for people that were clients of the CNIB. They used to have a $10 \%$ discount. So I used to shop there quite a bit.

Our dialogue evolved as we visited different sections of the mall. We explored a large pedway that connects the east and west side of the retail center. Eleanor discussed her preference for shopping with friends. We went up and down escalators as she talked about her desire to move back to Edmonton after spending many years in Saskatoon. It was at this stage in the research, that "place" most clearly influenced knowledge. In other words, it was through this process of "talking whilst walking" that we explored "the relationship between humans and place to uncover meanings and understandings of the life world" [8] (p. 255).

Our journey concluded in the food court, where Eleanor shared the major insights that are included in the film. It was after our journey through the mall that she described her experience of light, and use of public transportation. The dialogue that we fostered while exploring the busy 
mall, concluded with candid stories, told while seated in the quiet surroundings of the City Centre Mall food court. Through our collaboration, Eleanor provided significant knowledge on mobility and environmental conditions. However, the opportunity to casually walk, talk, and explore a place, also facilitated a shift from research formalities to relationship-building-this shift led to interactions that were often driven by casual dialogue and personal stories.

THE STORYTELLER TAKES THE LEAD (CAROL'S JOURNEY): Each participant in this study possesses unique qualities that were captured in the film. In the case of Carol, she was the exuberant, wholehearted, and committed storyteller. The footage she recorded during a dance class illustrates the creative energy she injects into daily activities. Meetings with Carol extended well beyond the formalities of predetermined questions. Observations and ideas were often the catalyst for stories, critical discussions, and at times, chitchat.

Carol was the third participant to join this research, in late 2012. I first met her on a weekday morning at a busy coffee shop in Sherwood Park, just outside the city of Edmonton. It was not difficult to establish a lively and engaging dialogue. Carol is a natural storyteller, and did most of the talking throughout our meetings. During our first twenty minutes she described her recent experience of applying for a telecommunication job. This rigorous and time-consuming process involved a range of interviews, security clearances, and exams. One of her tests was administered by an educational institution in Edmonton. Carol shared the challenging experience of searching for technology within the college to facilitate the test.

I had to pass a typing test and there was no visually impaired version of that. I tried disability services there and I said: "Do you guys have a visually impaired typing test? Like either where it's delivered orally or where it's large, or it's on a computer because the contrast can be changed. I have a retinal disorder so that's a really big thing for me." And the lady at disability services said to me, "oh dear, maybe this just isn't the job for you." And I'm like "oh for God's sake."

Many of the stories shared by Carol revolve around her willingness, and ability, to overcome obstacles. During our conversations she made this clear by stating that "you have to work to your full potential, and sometimes it means knocking on doors, asking questions-I think it's very important to go out and strive". Carol has also helped others overcome obstacles. At her gym, she recently organized a fundraiser and opened a trust fund for a gentleman, who is raising two small children on his own after his wife, who was legally blind, accidentally fell into the Edmonton LRT tracks in 2012.

Carol has full knowledge of the sighted world. She became legally blind as an adult. Some of our discussions made reference to this process of change and adaptation.

I lost my sight when I was twenty-seven. So I had all that independent stuff. I went away to school. I went to post-secondary, I drove a car. I did all that stuff. Not that I was pleased with it-it was a difficult transition. I mean I went through a lot of things, but on the other side of it I'm pretty okay with it. I had my chance to do those things.

Carol has been able to maintain her career throughout this transition. She studied music at Grant MacEwan University, the University of Alberta, and Humber College in Toronto. She currently provides private voice lessons from her home studio in Sherwood Park. It is not her intention to quit music, but she is hoping to cut down on the number of students she teaches, and acquire better health benefits by taking on the telecommunications job.

Conversations with Carol were engaging, positive, and often made reference to projects-recently completed or future ones. The process of applying to this new job was the project she had just started when we met. Activities at the gym, dragon boating, and the filming of Light in the Borderlands are examples of other projects that reflect her active and passionate disposition. Carol's joie de vivre also comes through in her storytelling - our urban journey involved a trip to her gym, where she recorded hand-held footage while dancing at a Zumba class. There is a palpable enthusiasm in her voice, and 
an openness to share thoughts and experiences. The last sentence of a recent email message highlights her eagerness to articulate what's on her mind: "thank you for allowing me to tell my story, it was very freeing and therapeutic for me".

\subsection{The Voice of Researchers and the Use of a Camera}

After sharing the three journeys that make up Light in the Borderlands, we conclude this section with a description of our own role, as researchers, in the making of this film. We will briefly discuss the way in which our voices are implicit within this work-particularly at the post-production stage. We will also talk about the role that the camera played in this research.

In the making of Light in the Borderlands participants speak of personal experiences while responding to the presence of a researcher (author one). This ethnographic response is highlighted by Hammersley and Atkinson when they write that "in interviews the very structure of the interaction forces participants to be aware of the ethnographer as audience" [13] (p. 176). From this point of view, the researcher becomes an unheard voice, insinuated throughout the ethnography. The relationship between participants and this unheard voice is an important part of Light in the Borderlands.

The researcher's voice is also expressed in the very structuring of this film. Though not heard, this voice is implicit in the editing of image and sound. What is presented in the film as three continuous monologues is in fact the product of several hours of conversation, reflection, and casual chatting. The results of this verbal interaction were recorded and subsequently pieced together in order to tell each of the three stories. The choice to include specific parts of each interview and to omit the researcher's voice was considered integral to the focus of this project; namely, conveying the urban experiences of participants.

The editing of this film involved collaboration and extensive discussions between the researchers, (authors one and two). Aerlan Barrett, a young filmmaker, also provided valuable feedback and suggestions after seeing an initial draft of the film. The distinct soundscapes created for each journey emerged from his critique. The voices of authors one and two, along with Aerlan Barrett, therefore, are also implicit in the editing of Light in the Borderlands. Shafi, Eleanor, and Carol were involved in the recording and narrating of the film, but not in its post-production. Due to the multi-layered nature of Light in the Borderlands (made up of different stories, each with a unique sense of time, place, and movement) we took on the role of editing in order to provide a cohesive voice-a sense of continuity-that carries across all three stories. After making this first collaborative film, however, we are interested in expanding participant involvement (in future projects) beyond the production phase, and into the editing of the work.

Involving participants in the editing of the film would allow for further exploration of the shifting boundary between participants and researchers. In the context of this project, the boundary between participants and researchers often became dissolved at the production stage of Light in the Borderlands. The line separating participant and researchers was blurred as the latter largely determined the content and context of the film. Participants often played the role of researchers by steering both conversations and journeys.

This shifting boundary was also embodied in a cultural artifact that epitomizes visuality: the digital camera. This is another important actor not seen in the film. With this technology participants captured journeys that reveal mobility (as in Eleanor's walk through the mall), aesthetic exploration (as in Shafi's footage of the gallery), and kinesthetic sensation (as in Carol's movement during a Zumba class). The camera reinforced the practice-based nature of this research by providing participants with an opportunity to document their own practices of navigating through built environments, making art, and dancing.

The standard definition Sony Handycam used in the recording of this film is a small, easy to operate camcorder. The camera facilitated a straightforward recording of urban journeys. Requiring one simple step before use (the pressing of a red button), the device also facilitated a rapid exchange between a researcher and participant as the camera could easily be handed back and forth. At times 
the device acted as an object of exchange and transition, as conversations led to recordings, or technical explanations of the zoom lens were followed by the capturing of footage. The quality of these interactions reflect Arjun Appadurai's notion that objects possess a "social life" [14] (p. 15). During the recording stage of this project the relationship between participant and researcher was often mediated by the camera. In other words the camera was a key actor in this investigation, enhancing interaction and dialogue between people.

After initial meetings and conversations, the camera helped to dissolve the boundary between researcher and participant, enabling the latter to document his or her experience of the built environment. The ethnographic encounter shifted when the camera was handed over to participants-it was at this key juncture in the project that participants began to play a more active role as filmmakers and co-investigators.

\section{Present Actors}

\subsection{Image, Darkness and Light}

The imagery of Light in the Borderlands is a documentation of architecture, a demonstration of technological use, and a digital trace of each participant's movement through space. The footage from each journey illustrates the interplay between various actors: built environment, technology, and participant. In this section, we discuss the type of visuals captured by each participant in the film. We begin with a description of Shafi's creative explorations at the art gallery, followed by Carol's dynamic storytelling at the gym, and Eleanor's walk through the mall. We conclude with a more detailed description of Eleanor's reference to darkness and light. In recording these journeys, a particular type of recording device was used to capture darkness and light: a standard definition camera (which, as mentioned in the introduction, captures relatively low-resolution visuals). Light in the Borderlands was recorded with a digital recording device that produces noisy, grainy images, particularly unclear during sudden light shifts. These fuzzy images embody a range of explorations that suggest a relationship of the optical to other sensory experiences such as kinesthetic sensation, haptic vision (suggestive of touch), and aesthetic sensibility [11] (p. 129).

INVISIBLE LINES (Shafi's footage): Midway through the film we find the most salient example of an aesthetic interaction between architecture, technology, and participant. Shafi's recordings at the Art Gallery of Alberta reveal a sensitivity to form and composition, beginning with the image of a staircase dissolving into a spatial exploration of the gallery's curved shapes. These images provide a sense of on-screen abstraction as rectilinear walls cut across undulating surfaces. These aesthetic explorations embody a haptic vision, facilitated by the digital camera. Suggesting the sense of touch, Shafi traces the building's formal structure by juxtaposing imagery that is soft and at times out of focus, with sharp, pointed edges of glass and stainless steel.

This carefully composed imagery was not the result of an incidental pointing-of-the-camera. Shafi's recordings embody the art of observing through "line-making" [1] (p. 225). As we learn in the second half of his journey, Shafi likes to draw. Inside the gallery, he uses the camera like a pencil, delineating architectural form by moving the camera, zooming, and walking. This is a mode of description and inscription as invisible lines trace the contours of the gallery's interior features.

DANCING IMAGES (Carol's footage): The images from Shafi's journey are the result of a prolonged examination of architectural space. In contrast to this sustained aesthetic exploration, the last story in the film reveals a dynamic kinesthetic journey. Carol's hand-held footage of movement during a dance class provides an experiential video documentation as well as a whimsical twist to the film's ending. Before dancing, Carol explores the space around her while the instructor prepares for class. Carol's turn of the camera to a wall of windows momentarily alters the light/dark contrast of the video. Briefly, she records her foot while probing the light, maple wood texture of the floor. Then, after one minute of meandering cinematography, the camera points to the front. The instructor is seen adjusting her headset microphone as she begins a repetitive forward and backward 
step. While holding the camera, Carol follows the instructor's increasingly intricate movement. This experiment of recording while dancing, led to footage that is in constant flux. Swinging from side to side, Carol's movement is not unlike Ingold's description of sawing a plank that, "[al]though rhythmic and repetitive-is never strictly monotonous" [1] (p. 53).

Unlike Shafi's delicate framing of the gallery space, Carol's cinematography (and story) is imbued with a sense of vitality. Her roving camera work embodies an exuberant, at times restless, approach to storytelling. These images also capture an informal and improvised style of filmmaking, reflecting approaches used in intercultural cinema, including what Julio Garcia Espinosa describes as "imperfect cinema" [11] (p. 10). Similarly, Laura Marks talks about "a by-any-means-necessary look" [11] (p. 10). These imperfect filmmaking methods, according to Marks are partly the result of an experimental visual language that attempts to capture "embodied knowledge and experiences of the senses" [11] (p. 2).

URBAN TRANSPARENCY (Eleanor's footage): There are several other moments in Light in the Borderlands that are captured in the spirit of intercultural cinema, and suggestive of sensory experiences. Eleanor's journey through a mall for example includes a wide range of still images that overlap and dissolve into footage that flows, pauses, and slows down. Her footage evokes the many layers of lived experience, memory, and geographical displacement articulated through her journey.

Eleanor's stories convey multiple levels of experience. For example, she evokes notions of home by describing the back and forth movement between cities; she also refers to the precariousness of winter conditions in her discussion of ice-covered sidewalks; and finally, she describes the unpredictable nature of public transportation. The mall provides an appropriate setting for her stories, as she records her movement through multiple levels of built space. Each level within the mall offers a unique visual backdrop for the experience described through spoken words.

Throughout this journey there is also a striking contrast between the many seconds of static imagery versus moving footage recorded while walking. Unlike the spaces explored by Shafi and Carol, Eleanor's built environment is experienced through extended periods of walking. Many parts of this journey were recorded by Eleanor while walking through corridors and open spaces of the mall. However, Eleanor's thoughtful, perceptive monologue also calls for visuals that are unhurried, calm and at times motionless. Often, the near static and dynamic footage are shown simultaneously, dissolving in and out of one another. There is a flow of imagery, color and texture during the second half of this journey. Cropped sections of the mall, typographic details, and shop displays appear to meld into an abstract field of urban movement. Such visuals call to mind the words of Juhani Pallasmaa who refers to "the tactile presence of modern visual imagery" within "the layered contemporary urban transparency" [15] (p. 36).

DARKNESS AND LIGHT: Eleanor's journey is the first story in the film. It is preceded by twenty-five seconds of black (in which titles appear). Through the use of black, it is not our intention to convey absence, for the use of black is as carefully considered as the inclusion of imagery. A black screen is part of a larger orchestrated experience, integral to the overall rhythm of the film-an idea conveyed by Jean-Luc Godard who said that "in film there's rhythm, it's more like music, that's how I came to use black for rhythm" [16] (p. 24).

Five seconds into the film, as the opening title appears against a black screen, a large public space is implied through a soundscape of distant, echoing voices. About twenty seconds later a fuzzy picture slowly dissolves out of the black, revealing an empty food court-human presence is limited to a distant figure standing motionless on the right side of the frame. A woman's voice is heard-it is Eleanor talking about her movement between Saskatoon and Edmonton. Movement also begins to appear on screen as the distant figure starts to walk at about three frames per second.

Eleanor's introduction is followed by video footage recorded while walking through a corridor that connects the food court to a large shopping area. She takes the viewer on a journey through a built environment that she enjoys spending time in: Edmonton's City Centre Mall. In this early part of 
the film Eleanor makes the most direct and literal reference to the film's title by talking about the significance of light. Specifically she discusses her experience of shifting conditions within the mall.

Sometimes I find with certain lighting I get a little bit disorientated, and I have to sort of just keep walking and looking at the stores to get my bearings again. And when the lighting changes-like even at the other mall sometimes if I go to a floor where I'm not there often it takes a while to get my bearings again. For me, some of the lighting I'm not sensitive to at all, and then other lighting, like this stuff here is hard. Sometimes when it's the real bright white ones, it seems to just have this weird effect and I don't know why but it just does. And sometimes I'm great, and I don't know what the difference there is either. Some days it affects me and some days it doesn't.

It may surprise some readers to learn that light is a significant and unpredictable part of Eleanor's daily life. People in the "borderlands of blindness" have "residual, usable vision" that is highly sensitive to environmental conditions [3] (p. 4). Eleanor's description illustrates how light is an embodied experience. Light, in other words, is not merely perceived; it is part of the environment that constantly interacts with body and movement [15] (p. 41). It is an example of Pallasmaa's phenomenological notion that "the percept of the body and the image of the world turn into one single continuous existential experience" [15] (p. 41).

Based on this notion, light is not simply a "phenomenon of the physical world" or a "phenomenon of the interior mind"; "light is an experience" —an experience that is comparable to other sensory ways of knowing, such as sound [2] (p. 128). Light and sound are significant actors in Light in the Borderlands. They not only mediate, but also dissolve the boundary between, participants and environments. In the following section, we will discuss how the auditory component of Light in the Borderlands, namely, voice and sound, function as actors.

\subsection{Voice and Sound}

At no point in Light in the Borderlands do we see Eleanor, Shafi, and Carol. We only identify them through their voices. Their identity in other words, is primarily conveyed through voice. The words spoken by each participant also provide the knowledge, narrative, and continuity that carry the film forward.

In this section we describe how each voice in the film represents a different reality, a unique way of experiencing and engaging with the urban world. Along with imagery, voice is a key actor through which homogenous notions of blindness are challenged. The words of each participant present three distinct ways of living in, and navigating through, built environments. Whereas Eleanor chose to talk about her experiences at a mall, Shafi explored memory and aesthetics through his visit to the Art Gallery of Alberta, while Carol discussed her experiences at gyms and other public spaces in Edmonton.

Participants in this research spoke of lived experiences, creativity, and independence. Through their words these individuals describe the complexity of blindness-they are, in the words of Linda Tuhiwai Smith, "countering the dominant society's image" [17] (p. 151). This dominant image includes the "medically constructed blindness/sightedness binary" [3] (p. 5). A counter position to the medical model, suggested by each voice in this story, is the idea that "blindness is an alternative way of being in and knowing the world-not inferior to sight" [3] (p. 152).

In the film, Carol provides several examples of this alternative way of knowing. She compares her life before becoming partially sighted (at twenty-seven) and after. She describes a range of physically engaging activities that have become part of her regular routine.

I never really engaged in sports or anything else, I was always a music person. So I got into the gym. I love things like dance, I love Zumba, I love what they call Sh'Bam which is a hip-hop sort of dance. I can't see myself that well so apparently I think I dance like a rock star (laughs). And it doesn't bother me, I'm like, whatever (laughs). And then the dragon 
boating. I'm a real fan, and that was exciting. Because, when they said they were having a visually impaired dragon boating team, I was like: how the hell are we all getting in the boat? That was the biggest point of intrigue. I had to join just to see how all of us were getting in the boat, and it was amazing. I met some really excellent people and it really inspired me to work to the full of my potential.

Carol's voice provides an example of participant-driven storytelling. It was through such stories that alternative conceptions of blindness were described. Storytelling, according to Tuhiwai Smith "is a useful and culturally appropriate way of representing the 'diversity of truth' within which the storyteller rather than the researcher retains control" [17] (p. 145). There was, throughout this project, an evolving relationship between participant (as storyteller) and researcher (as technical facilitator and director). As the project evolved, participants acquired greater control of the location and narrative content of the research. This process resulted in a documentary film that reflects participants' unique lived experiences through storytelling.

By highlighting the important role of voice, as an actor that carries identity, knowledge and stories, we also need to emphasize the presence of other sounds in the film. These sounds, together with participant voices, provide the auditory experience of Light in the Borderlands. Sound is another significant actor in the film. It provides an aural description of space. These spaces are often crowded, public environments. These are the spaces that to varying degrees, throughout a single visit, accommodate and challenge Eleanor, Shafi, and Carol. Within these spaces each participant, uses voice in different ways, expressing unique values, and articulating the qualities and affordances of particular locations. The background from which each voice emerges is a soundscape of other human voices, coffee shops, television, traffic, public announcements, and at times music. During our conversations with Eleanor, she described how the different sounds within a public space can meld into one.

There are times where if it's really, really noisy, let's say I'm with a group of friends, and there's a lot of us, and there's several conversations going on at once, then I can kind of hear it all, so then I don't hear anything. Does that make sense?

The soundscape created for the film is part reality and part fiction, in the sense that it was at times edited by author one in order to complement the voice of each participant. The traffic heard as Eleanor leaves the mall and approaches a bus stop for instance, was added in order to reinforce her verbal and visual account of public transportation. The background sounds heard in the film contribute to the concept of multi-vocality. This layering of sound (often recorded during interviews but at times added in post production) emphasizes the fact that each participant is connected not only to built spaces, but to the entire fabric of an environment.

\section{Conclusions}

We have come a long way since our introduction. Descriptions of the many actors behind Light in the Borderlands has led to stories of collaboration and filmmaking. There is, however, one more actor to discuss-blindness itself. Blindness elicits a range of contrasting, ambivalent ideas. On the one hand, through a medical model "society perceives legal blindness as pathology" [3] (p. 11). From this perspective, blindness is an obstacle or a boundary that prevents access to the sighted world. On the other hand, through a cultural model, we can speak of the ways in which blindness is a different way of knowing the world, with its own unique perceptual experiences. A person may shift from one model to another, as the writings of Jorge Luis Borges illustrate. Borges began to lose his vision in his early thirties. In his prologue to The Unending Rose he reflects on the difference between his literary description of blindness versus his lived experience.

Going over the proofs of this book, I notice with some distaste that blindness plays a mournful role, which it does not play in my life. Blindness is a confinement, but it is also a liberation, a solitude propitious to invention, a key and an algebra. [18] (p. 345) 
The description provided by Borges illustrates the tension between contradictory ideas of blindness. Through this brief quote he negotiates a unique path, that leads him from "confinement" to "liberation" [18] (p. 345). The paths travelled by Shafi, Eleanor, and Carol are also a form of negotiation. Each participant mediates his or her own pathway between the blind and sighted world. Light in the Borderlands depicts these unique journeys through explorations of urban space. Each journey communicates a unique interpretation of blindness.

Unlike objects, environments, and people, blindness, as an actor, lacks a tangible, material form. It is an embodied experience, comparable to light and sound [1] (p. 128). Each participant in this research shares a deeply personal account of blindness. These experiences are subjective and are best explored through storytelling.

Unlike the characteristics of a tangible actor, whose position in time and space can be described and documented, blindness is elusive. Like Eleanor's experience of light, blindness is a mutable, fluctuating actor. Blindness is interpreted differently by each participant in Light in the Borderlands. Each individual experience reveals deeper layers of story and movement through built environments. Our film provides an opportunity for participants to share fragments of their own unfolding story.

Ultimately, for the purposes of this research, we think about blindness as an embodied experience and an evolving path between two worlds (the sighted and blind worlds). Movement, therefore, is also characteristic of blindness. As Ingold writes in reference to the drawing of lines, blindness manifests "a history of becoming, rather than an image of being" [1] (p. 221). Blindness is the actor that is in a state of change-evolving, moving and "becoming" something new [1] (p. 221). In this research, Carol is one of the participants who embodies this dynamic idea of blindness. She articulates this notion when referring to new people she has met.

I met some really excellent people, and it really inspired me to work to the full of my potential. I saw the things they were doing and I was like-come on you can try a little harder and we can work to, at least, what our potential is. And that's all that matters because otherwise I think you become stagnant and become a hermit, and become really jaded, and I'm not wanting to be that way.

Through each journey, Light in the Borderlands has explored this notion of blindness as an evolving, positive movement. In this text we have explored the making of this film by referring to a range of other significant actors that move through our story. In the first section of this article we shared the dialogue and evolving relationship between participants and researchers. This dialogue was foundational to our project. It was through this dialogue that the stories, journeys and filming of Light in the Borderlands emerged. Conversations between participants and researchers generated knowledge of urban spaces, lived experiences and stories. Through these encounters we addressed another of Michalko's propositions by exploring how storytelling "elevates blindness to the position of something that provokes thought" [9] (p. 4).

The second half of the first section involved descriptions of the camera and the researcher's voice. These actors, who are not heard or seen in the film, are implicit in the structuring of Light in the Borderlands. The researcher's voice is evoked through the overall editing process, and the juxtaposition of imagery and sound. The camera on the other hand, plays an intermediary role between participant and researcher, at times dissolving the boundary between the two. It was through the use of the camera that participants became co-investigators, as they captured visual material.

The second section explored actors that are present in the film. We began with a description of the film's imagery. The unique approach taken by Shafi, Carol, and Eleanor in recording footage resulted in visuals that capture the flux and energy of urban travel. Imagery is the most conspicuous actor of our story, and provides a visual embodiment of each journey.

Our next two actors, darkness and light, evoke the contrast between the blind and sighted world while representing the experience of walking through illuminated interior spaces. We make reference to the shifting mosaic of grey pixels that render the digital storyworld of Light in the Borderlands. Within 
this context, darkness is an actor whose presence is carefully timed, and considered integral to the overall rhythm of the film.

We continued with an account of voice and sound. These are the actors that carry the film forward. In itself, voice is the key storytelling component of Light in the Borderlands, conveying past experiences, emotions, and memory through oral delivery. The soundscape from which these voices emerge are described as a melding of other sounds, pieced together and edited at the post-production stage.

Finally, as part of this conclusion we have made reference to blindness itself. Blindness, however, was not the actor driving these stories. It was Eleanor, Shafi, and Carol driving the stories. Each of them shared experiences that were vastly different from one another. Through these differences we learn that storytelling elevates the lived experiences and abilities of each participant as they shop, walk through the city, work, talk about art, and dance.

It was through the movement and stories told by Eleanor, Shafi, and Carol that subjective interpretations and personal experiences of the built environment became the content for our film. Light in the Borderlands, above all, embodies the intangible and untold stories of blindness. These are stories of creativity, laughter, and inspiration.

Light in the Borderlands can be viewed at [19].

Acknowledgments: This work was partially funded by a Killam Cornerstone Grant at the University of Alberta. The authors would like to thank the Canadian National Institute for the Blind (CNIB) and the participants for their generous support of the project. Participants chose to remain anonymous in this film and for this manuscript. We would also like to thank Aerlan Barrett for his film editing assistance.

Author Contributions: This project comes under the research program of Megan Strickfaden on design, material culture, and disability. The filmmaking and storytelling component of this project was led by Adolfo Ruiz, whose work involves creative collaborations in the Dene region of Canada's Northwest Territories. The film was shot by participants with Adolfo Ruiz. The research project design, data analysis, and writing was done collaboratively. Both authors have read and approved the final manuscript.

Conflicts of Interest: The authors declare no conflict of interest.

\section{References and Notes}

1. Ingold, T. Being Alive: Essays on Movement, Knowledge and Description; Routldege: New York, NY, USA, 2011.

2. Latour, B. Reassembling the Social: An Introduction to Actor-Network-Theory; Oxford University Press: Oxford, UK, 2005.

3. Omansky, B. Borderlands of Blindness; Lynne Reiner Publishers: Boulder, CO, USA, 2001.

4. Rabinow, P. Representations Are Social Facts: Modernity and Post-Modernity in Anthropology. In Writing Culture: The Poetics and Politics of Ethnography; Clifford, J., Marcus, G.E., Eds.; University of California Press: Berkeley, CA, USA, 1986; pp. 234-261.

5. $\quad$ Pink, S. Doing Visual Ethnography; Sage Publications: London, UK, 2007.

6. Frayling, C. Research in Art and Design. R. Coll. Art Res. Pap. 1993, 1, 1-5.

7. Devlieger, P.; Rusch, F.; Pfeiffer, D. Rethinking disability as same and different! Towards a cultural model of disability. In Rethinking Disability: The Emergence of New Definitions, Concepts and Communities; Devlieger, P., Rusch, F., Pfeiffer, D., Eds.; Garant: Antwerp, Belgium, 2003; pp. 9-16.

8. Anderson, J. Talking whilst walking: A Geographic Archaeology of Knowledge. Area 2004, 36, $254-261$. [CrossRef]

9. Michalko, R. The Mystery of the Eye and the Shadow of Blindness; Toronto University Press: Toronto, ON, Canada, 1998.

10. Linde, C. Life Stories: The Creation of Coherence; Oxford University Press: Oxford, UK, 1993.

11. Marks, L.U. The Skin of the Film: Intercultural Cinema, Embodiment, and the Senses; Duke University Press: Durham, NC, USA, 2000.

12. This research was done one-on-one between Adolfo Ruiz and the participants. When the first person is used in this section it is written from the perspective of Adolfo Ruiz (author one).

13. Hammersley, M.; Atkinson, P. Ethnography: Principles and Practice; Routledge: New York, NY, USA, 2005.

14. Appadurai, A. The Thing Itself. Public Cult. 2006, 18, 15-21. [CrossRef]

15. Pallasmaa, J. The Eyes of the Skin: Architecture and the Senses; John Wiley \& Sons: Chichester, UK, 2005. 
16. Godard, J.L.; Ishaghpour, Y. Cinema: The Archeology of Film and the Memory of a Century; Berg: Oxford, UK, 2005.

17. Smith, L.T. Decolonizing Methodologies: Research and Indigenous Peoples; Zed Books: London, UK, 1999.

18. Borges, J.L. The Unending Rose. In Jorge Luis Borges: Selected Poems; Coleman, A., Ed.; Penguin: London, UK, 1999.

19. Film. Available online: http://meganstrickfaden.com/Film (accessed on 31 December 2015).

(C) 2016 by the authors; licensee MDPI, Basel, Switzerland. This article is an open access article distributed under the terms and conditions of the Creative Commons by Attribution (CC-BY) license (http:/ / creativecommons.org/licenses/by/4.0/). 